\title{
Mathematics Content Knowledge Prospective Teachers Through Project-Based Learning Assisted By GeoGebra 5.0
}

\author{
Sumarni $^{1,2}$, Darhim ${ }^{1}$, Siti Fatimah ${ }^{1}$, Sri Adi Widodo ${ }^{1,3}$, Mohamad Riyadi ${ }^{2}$ \\ \{marnie.1205@gmail.com, sitifatimah@upi.edu, sriadi@ustjogja.ac.id, \\ mohamadriyadi@uniku.ac.id\} \\ ${ }^{1}$ Universitas Pendidikan Indonesia, Bandung, Indonesia \\ ${ }^{2}$ Univeristas Kuningan, Jawa Barat, Indonesia \\ ${ }^{3}$ Universitas Sarjanawiyata Tamansiswa, Yogyakarta, Indonesia
}

\begin{abstract}
Prospective mathematics teachers must have a mathematics content knowledge in preparation to become a teacher, which requires students be able to master the subject matter in-depth and breadth. The purpose of this study is to find the difference mathematics content knowledge of prospective mathematics teacher after participating in project-based learning assisted by GeoGebra 5.0 on solid geometry material. This study was quasiexperimental research, with pre-experimental design; the one group pre-test-post-test. The sample of this study consist of 27 prospective mathematics teachers. The analysis data used the normality test, homogeneity test, and t-test. The result shows that project-based learning assisted by GeoGebra 5.0 had a significant influence on the MCK of prospective mathematics teachers. Project-based learning assisted by GeoGebra 5.0 provided experiences to prospective mathematics teachers in constructing solid geometry concepts to develop mathematics content knowledge. Mathematics content knowledge consists of three domains namely: knowing, applying, and reasoning.
\end{abstract}

Keywords: Mathematics Content Knowledge, Project-Based Learning, GeoGebra 5.0

\section{Introduction}

Mathematics content knowledge is one of mathematics knowledge for teaching (MKT). MKT consists of mathematics content knowledge (MCK) and mathematics pedagogical content knowledge (MPCK) [1]. Prospective mathematics teachers must have an MCK in preparation to become a teacher. In Indonesia, prospective teacher students must have professional competence, which requires students to be able to master the subject matter in-depth and breadth. So that it can guide students to meet certain competency standards.

The improvement of teaching knowledge which covers content knowledge or professional competence and pedagogical content knowledge or pedagogical competence can be done not only in teacher professional development program but also in teacher education program [2]. So, to result from a competent teacher can begin from the teacher training program $\mathrm{s} / \mathrm{he}$ joins. 
MCK uses a cognitive domain that includes knowing, applying and reasoning [1]. This MCK research on prospective mathematics teachers was focused on teacher candidate mathematics material mastery, thus MCK was meant as an ability to give the definition in mathematics (knowing), represent mathematics idea appropriately (applying), and make a connection of interconnected mathematical ideas (reasoning).

Some researches on MCK are seen in the research [3], [4], [5], [6]. Study MKT students of primary and secondary school teachers in Malaysia, show that the average MKT (MCK and MPCK) of prospective primary and secondary school teachers are below the average scores for international [3]. Comparative study of two learning was carried out namely Problem based learning and conventional learning to find out the MKT profile (MCK and MPCK) and mathematics beliefs of prospective primary teacher students, the results showed that the MCKK and MPCK of prospective teacher students with problem-based learning were better than conventional learning [4].

Teachers have a role important in the learning system, especially improving learning quality [7]. Efforts to improve learning quality by combining learning models with technology.

One learning model that facilitates that used to develop MCK and what is combined with technology is Project-based learning (PjBL). PjBL is a model that organizes learning around projects [8]. Through project-based learning, students drive their own learning through inquiry, as well as work collaboratively to research and create projects that show their knowledge. From gleaning new, viable technology skills, to becoming professional communicators and advanced problem solvers, students benefit from this approach to instruction [9]. The elements of projectbased learning models are an introduction, task, resources, process, guidance and scaffolding, cooperative/ collaborative learning, reflection [10].

GeoGebra is a dynamic learning environment that enables users to create mathematical objects and interact with them. GeoGebra users, mostly teachers or students, can use this environment to explain, to explore, and to model mathematical concepts and relationships between them, or mathematics in general [11]. GeoGebra used in learning for visualization, demonstration, construction tools, exploration, and discovery. The use of GeoGebra in learning provides two experiences for students, namely techniques using GeoGebra and constructed mathematical concepts [12]. Students can construct and find the concept of solid geometry using GeoGebra 5.0 because it is equipped with a worksheet menu for 3D geometry.

Some examples of using GeoGebra for visualization and demonstration was found in the article [13]. The use of GeoGebra as a construction tool can be seen in the article [12]. While the use of GeoGebra for exploration and discovery can be seen in an article [14].

Based on the explanation above, project-based learning assisted by GeoGebra 5.0 can develop mathematics content knowledge of prospective mathematics teacher students. So that in this paper the researcher describes mathematics content knowledge of prospective teacher students using project-based learning assisted by GeoGebra 5.0.

\section{Method}

This research is a quasi-experiments research in the form of a pre-experimental design: the one group pre-test-post-test [15]. Briefly, the research design carried out can be defined as below:

$\mathrm{O} \times \mathrm{O}$

Explanation: 
X: project-based learning assisted by GeoGebra 5.0

$\mathrm{O}$ : pre-test $=$ post-test mathematics content knowledge

The research sample consisted of one class from one university in West Java, Indonesia. A total of 27 students were involved, namely students in space geometry courses. These study samples were given treatment with project-based learning assisted GeoGebra 5.0. The analysis data used normality test, homogeneity test, and t-test

This study involves mathematics content knowledge of solid geometry material (definition, a concept of area and volume). The pre-test and post-test instruments provided are the same instrument and have gone through the test phase of validity, reliability. There are three questions on pre-test and post-test to measure MCK.

1. Knowing; recall definitions, terms, and geometry

"Explain define of cubes and cuboid"

2. Applying; solve routine problems

"It is known that the length of the cuboid equal to twice the width and height of the rectangular prism s by the width. The size of the cuboid changes its length to three times the original and the width becomes twice the original, while it remains. If the cuboid surface of an area is originally $448 \mathrm{~cm}^{2}$, find the volume of the cuboid after enlarging."

3. Reasoning; solve non-routine problems

Pay attention to the picture below
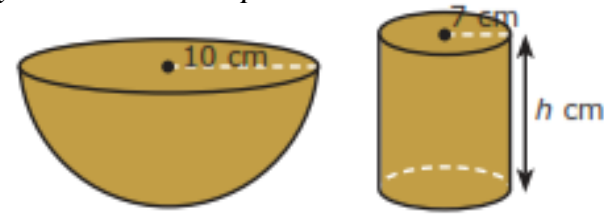

The picture above is a half sphere with a radius of $10 \mathrm{~cm}$. And cylinder with radius $7 \mathrm{~cm}$ and height $\mathrm{h} \mathrm{cm}$. If the cylinder has the same volume as the volume of half the sphere. Determine the height of the cylinder?

\section{Results and Discussion}

\subsection{Results}

Data analysis using SPPS version 20 used for 1) Descriptive analysis, 2) Test requirements data analysis (test of normality and homogeneity), and 3) hypothesis test used t-test. The following table is the result of pre-experimental and post-experimental mathematics content knowledge score.

Table 1. Normality and Homogeneity Pre-test and Post-test

\begin{tabular}{ccc}
\hline Test & $\begin{array}{c}\text { Sig. Test for } \\
\text { Normality }\end{array}$ & Sig. Homogeneity \\
\hline Pre-test & .200 & .348 \\
Post-test & .200 & \\
\hline
\end{tabular}

Based on Table 1. the result of the data normality test pre-test and post-test scores of the mathematics content knowledge had shown that both probabilities score more than 0.05 . It can 
be concluded that in both (pre-test and post-test) is normally distributed. For the variance homogeneity test is show that data were homogeneous.

Table 2. Differentiation Pre-test and Post-test Result

\begin{tabular}{lllllll}
\hline Test & N & Mean & SD & df & t & Sig.(2-tailed) \\
\hline Pre Test & 27 & 43.96 & 15.907 & 52 & -6.165 & .000 \\
Post Test & 27 & 69.19 & 14.101 & 52 & & \\
\hline
\end{tabular}

Based on Table 2., it seems that there is a statistically significant difference between the students' success scores in the pre-experimental process and the value in the post-experimental process $(t=-6.165, \mathrm{p}<.05)$ as long as the difference is seen that students are more successful in the post-experiment process $\left(\mathrm{x}^{-}=69.19\right)$, than the pre-experimental process $\left(\mathrm{x}^{-}=43.96\right)$. This finding could mean that the lessons learned in the project based Learning Assisted GeoGebra 5.0 had a significant influence on the MCK of prospective mathematics teachers.

Table 3. Comparison of Percentage of Answer Results Tests of Mathematics Content Knowledge

\begin{tabular}{llccc}
\hline \multirow{2}{*}{ Number test } & \multicolumn{2}{c}{ Pretest } & \multicolumn{2}{c}{ Posttest } \\
& Correct & Incorrect & Correct & Incorrect \\
\hline $1 \mathrm{a}$ & $18.52 \%$ & $81.48 \%$ & $85.19 \%$ & $14.81 \%$ \\
$1 \mathrm{~b}$ & $8.11 \%$ & $91.89 \%$ & $74.07 \%$ & $25.93 \%$ \\
2 & $22.22 \%$ & $77.78 \%$ & $62.96 \%$ & $37.04 \%$ \\
3 & $14.81 \%$ & $85.19 \%$ & $59.26 \%$ & $41.74 \%$ \\
\hline
\end{tabular}

The following chart represents the percent correct and incorrect in the pretest of mathematics content knowledge of prospective mathematics teachers.

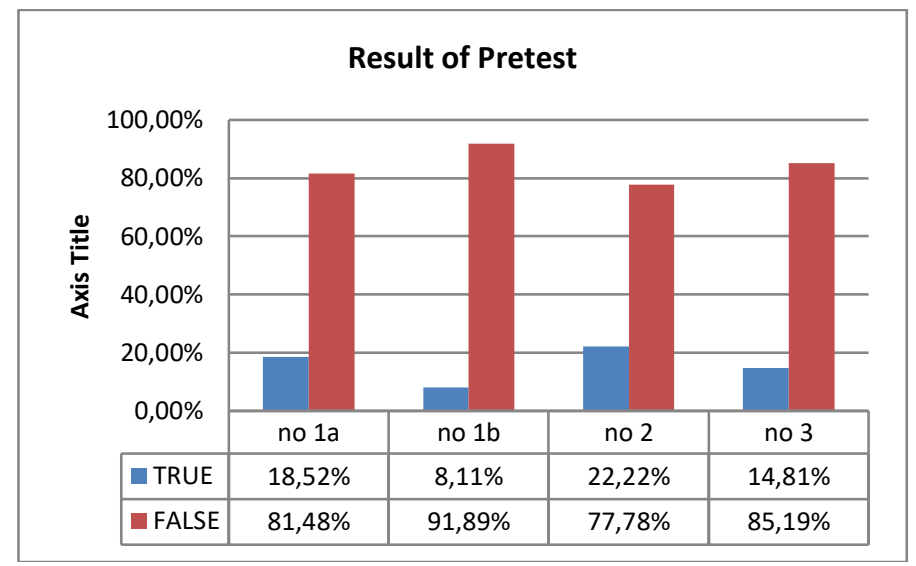

Figure1. The Percentage of Answer Results Pre-tets of Mathematics Content Knowledge

Based on the percentage of answer results pretest of mathematics content knowledge, the percentage of correct answers pretest number 1a, 1b, 2, and 3 were $18.52 \%, 8.11 \%, 22.22 \%$, and $14.81 \%$. This shows that the mathematics content knowledge of prospective teacher students in solid geometry material is still low. 
The following chart represents the percent correct and incorrect in the post-test of mathematics content knowledge of prospective mathematics teachers.

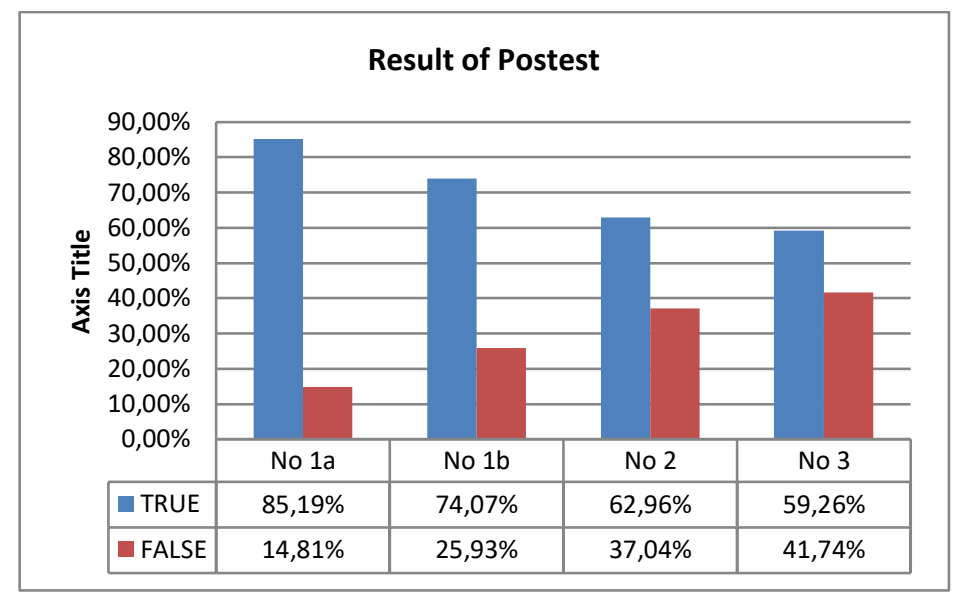

Figure 2. The Percentage of Answer Results Post-test of Mathematics Content Knowledge

Based on the percentage of answer results pretest of mathematics content knowledge, the percentage of correct answers pretest number 1.a, 1.b, 2, and 3 were $85.19 \%, 74.07 \%, 62.96 \%$, and $59.26 \%$. it shows that project-based learning assisted by GeoGebra can improve mathematics content knowledge of prospective teachers in solid geometry material.

\subsection{Discussion}

The result shows that project-based learning assisted by GeoGebra 5.0 had a significant influence on the MCK of prospective mathematics teachers. This result is possible because through project-based learning assisted GeoGebra 5.0, prospective mathematics teachers are facilitated in constructing solid geometry concepts (definition, area, and volume of solid geometry) to develop mathematics content knowledge.

In the learning process of project-based learning assisted by GeoGebra 5.0 on solid geometry, prospective teachers are given project assignments that challenge to work in groups to create plans, solve problems they meet, test their ideas, and present their projects to peers. The learning process through exploration, construction and discovery projects about the concepts of solid geometry (definition, elements, and nets) and find the base and height of the solid shapes, 2) find the area of the solid shape, and 3) find the volume of solid shapes.

At first, they (prospective mathematics teachers) were not able to communicate every solid shapes definition even though they understood it comprehensively. The role of the lecture here directs students through interactive discussions on how to make definitions of solid shapes by identifying the areas that limit them and the characteristics possessed by solid shapes. Prospective teachers have an understanding of the definition of solid shapes so that in determining the elements of solid shapes, prospective teachers do not meet difficulties, as well as for the base and height of the solid shapes.

The following is an example of the activities of prospective mathematics teacher students in constructing cube nets.

a. Open the 3D graphics window 


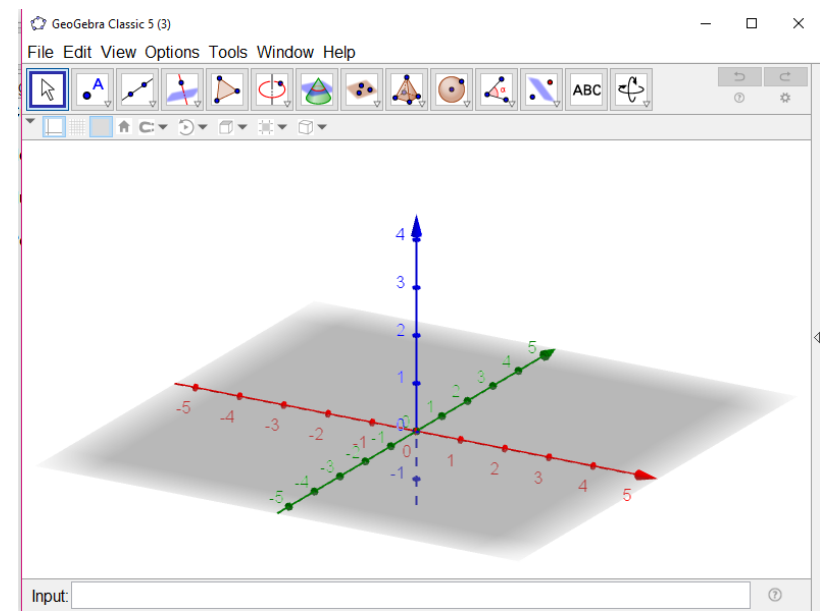

Figure3. 3D Graphics Window in GeoGebra 5.0

b. Construction the Cube

Construction of a cube using the tool that contains the cube icon

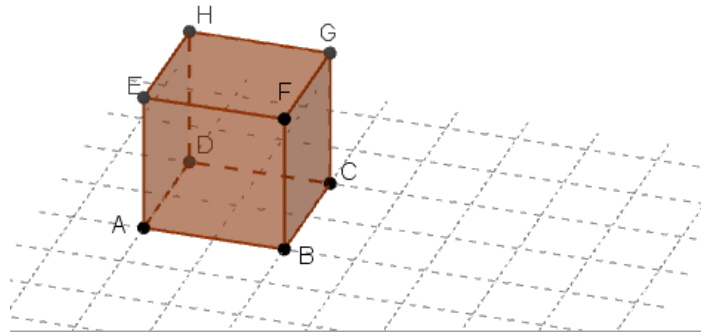

Figure 4. Construction Cube Used GeoGebra 5.0

\section{c. Making Cube Nets}

To make cube nets, click the tool that has the net icon, click on one side of the cube that the network will form.

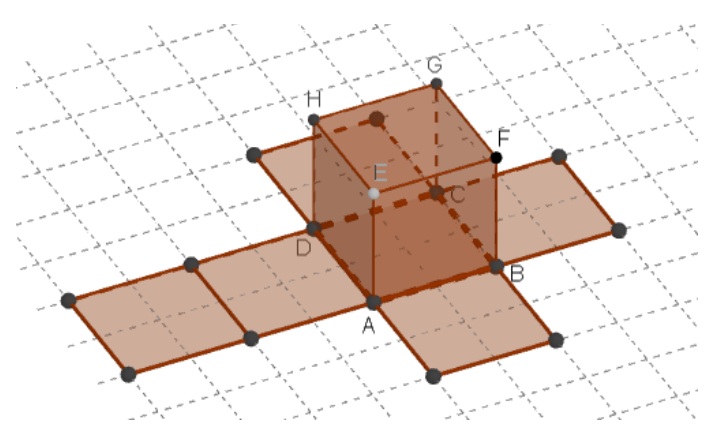

Figure5. Construction Cube Nets Used GeoGebra 5.0

d. The Formed of the Cube Nets 


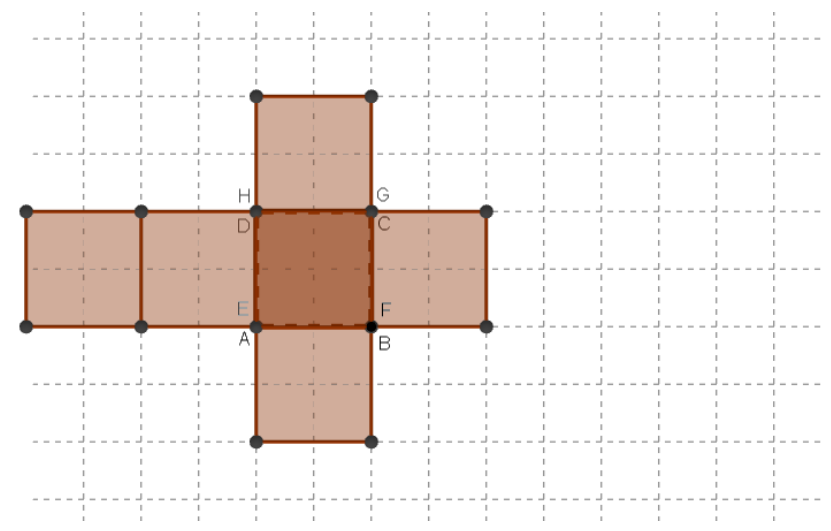

Figure 6. Cube Nets

Based on the activity of constructing cube nets, students can find a cube definition and construct the formula surface area and volume of the cube. The same activity can be done to build other spaces.

The experiences of prospective mathematics teachers using project-based learning assisted by GeoGebra 5.0 can give a deep understanding of the concepts of definitions, elements, and nets of each 3D geometry space that is (cubes, cuboid, prisms, pyramid, cylinders, cones, and spheres). It can be seen in the increase on the percentage of students who answered correctly for questions number 1 .a from $18.52 \%$ to $85,19 \%$ and $1 . b$ from $8.11 \%$ to $74.07 \%$ regarding cube and cuboid definition.

Prospective teachers make definitions of cube and cuboid by identifying the areas that limit them and the characteristics possessed by solid shapes. They also draw cube and cuboid shapes first and draw them to define. The following examples of the answer for now. 1.a and 1.b.

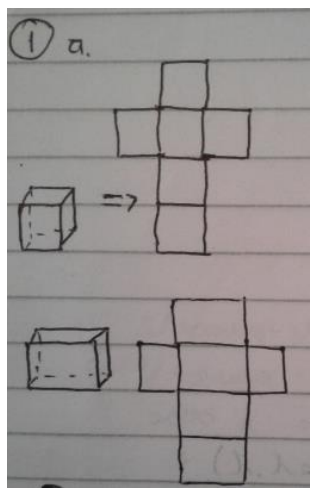

1a. The cube is a 3 -dimensional that has 6 sides of the same size, has 8 angles, 12 edges that are the same length, and the sides are square

1b. The cuboid is a 3 -dimensional that has 8 angles, 12 edges and 3 pairs of sides with at least one pair of sides of different sizes

The experiences of prospective mathematics teachers using project-based learning assisted by GeoGebra 5.0 can give a deep understanding of the concepts of definitions cube and cuboid. This is possible because through project-based learning is centered on the learner and affords learners the opportunity for in-depth investigations of worthy topics [10] and the used of GeoGebra in learning provides experiences for students, on constructed mathematical concepts [12]. 
The following is one of the results of the answer to question no.2 for indicator applying; using geometry to solve routine problems.

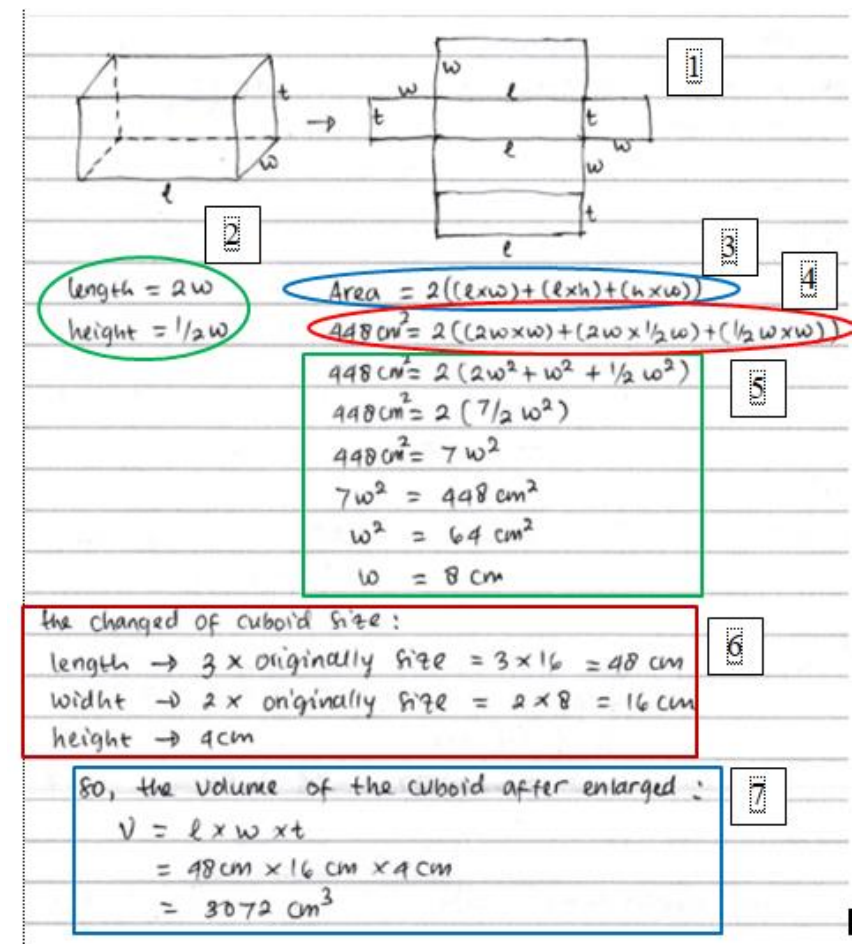

Figure7. The Answer of Question no.2 for Indicator Applying

The following is the explanation the answer of question no.2 indicator applying: solve a routine problem.

1 : Draw the shape of cuboid into nets

2 : Identify the values of length, width, and height of the cuboid

3 : Write the formula for the area of a cuboid

4 : Substitute $448 \mathrm{~cm}^{2}$ for area and $2 l$ for length, $1 / 2 l$ for height

5 : Evaluate values width and include the correct units

6 : Identify the values of length, width, and height of the new cuboid

7 : Answer the question with the correct units: write the formula for the volume of a cuboid; substitute 48 for length, 16 for width and 4 for height; calculate the volume of the cuboid after enlarging

Based on figure 8 . the answers of prospective teachers to find the area of cuboid by changing the shape of cuboid into nets first. Understanding cuboid nets have been owned by prospective teachers. Because in the learning process through project-based learning assisted by GeoGebra 5.0 are given exploration, construction and discovery formula of an area through nets construction.

The following is one of the results of the answer no.3 for indicator reasoning; using geometry to solve non-routine problems. 


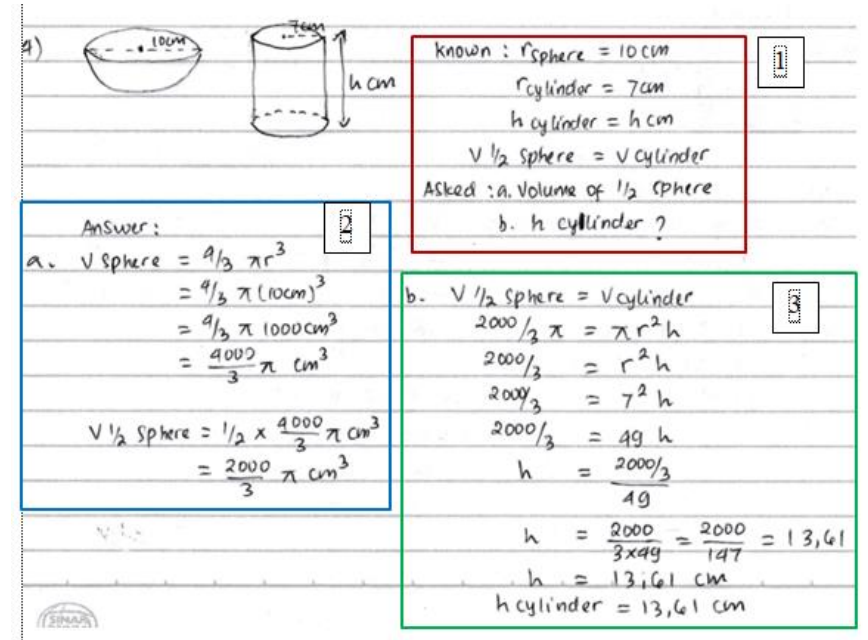

Figure 8. The Answer of Question no.3 for Indicator Reasoning

The following is the explanation the answer of question no.3 indicator reasoning: solve a non-routine problem.

1 : Identify the size of the radius of the sphere, the radius, and height of the cylinder, and find the question of the problem given

2 : Write the formula for the area of a sphere, substitute 10 for the radius, check the volume of the sphere, calculate the volume of half the sphere

3 : write the equation of the volume half the sphere equals the volume of the cylinder, substitute $(2000 / 3) \pi$ for half the sphere equals $\pi r^{2} t$, calculate and check the height of the cylinder

Based on figure 9. The prospective teachers solve the problem number 3 through steps 1-3 systematically so that they get the correct answer. It is consistent with [16] stating that to solve a mathematical problem requires a systematic way or steps to make the process of solving the problem become easy and focused.

Project-based learning assisted GeoGebra 5.0, are facilitated in constructing solid geometry concepts (definition, area, and volume of solid geometry) to develop mathematics content knowledge of prospective mathematics teachers. The prospective teacher's students were highly engaged in the process of exploration, construction, and discovery of the concept of solid geometry. Project-based learning is a teaching method that taps into students' interests because it allows them to create projects that result in meaningful learning experiences [17]. A project where students pursue a long-term investigation of a significant question and produce artifacts that represent the answer to those questions have to potential to motivate students and help them better understand content knowledge [18].

While the use of GeoGebra can offer opportunities for students to explore and to construct the concept of solid geometry. This is in accordance with the opinion of [12]-[14], [19] GeoGebra can be used to construct geometry dynamically, as a key element of geometry learning, visualization, estimation, conjecture, construct, discovery and verification. Advances in information and communication technology (ICT) can help students and teachers to do calculations, analyze data, explore mathematical concepts to improve understanding in learning mathematics [20]. This is in accordance with [21], [11] that the visualization and exploration of objects and mathematical concepts in a multimedia environment can develop understanding 
through new ways. Technology can make a substantial contribution to ameliorating these problems associated with project-based learning [18]. Therefore, project-based learning assisted by GeoGebra 5.0 can be used to develop mathematics content knowledge of prospective teachers.

\section{Conclusion}

Based on the result and discussion of research above, it can be concluded that project-based learning assisted by GeoGebra 5.0 provided experiences to prospective mathematics teacher students in constructing solid geometry concepts (definition, area, and volume of solid geometry) to develop mathematics content knowledge. Project-based learning assisted by GeoGebra 5.0 recommended applying in the process of solid geometry learning in university to develop mathematics content knowledge of prospective teachers.

\section{Acknowledgment}

Thus the Authors can convey about the result of research enclosed in this article. On the occurrence, the authors would like to express the appreciation and gratitude to Universitas Kuningan, LPDP, BUDI-DN as sponsors and all the parties that have a big impact to the success and accomplishment of this research. The author realizes that this article is far from perfect, therefore constructive criticism and suggestions are desirable for the perfection of this article. Hopefully, this research will be valuable for the reader.

\section{References}

[1] M. T. Tatto, The Teacher Education and Development Study in Mathematics (TEDS-M): Policy, Practice, and Readiness to Teach Primary and Secondary Mathematics in 17 Countries. Technical Report. 2013.

[2] H. C. Hill, D. L. Ball, and S. G. Schilling, "Unpacking pedagogical content knowledge: Conceptualizing and measuring teachers' topic-specific knowledge of students," J. Res. Math. Educ., vol. 39, no. 4, pp. 372-400, 2008.

[3] K. E. Leong, C. M. Chew, and A. R. Suzieleez Syrene, "Understanding Malaysian Pre-Service Teachers Mathematical Content Knowledge and Pedagogical Content Knowledge,” Eurasia J. Math. Sci. Technol. Educ., vol. 11, no. 3, pp. 363-370, 2015.

[4] I. Novikasari, "The Profile of Mathematical Knowledge for Teaching and Mathematical Beliefs of Pre-Service Primary Teachers," Int. J. Sci. Innov. Technol., vol. 3, no. 7, pp. 73-92, 2016.

[5] M. Hoover, D. L. Ball, and Y. Lai, "TME, vol. 13, no. 1\&2, p. 3," vol. 13, no. 1, pp. 3-34.

[6] P. H. Wilson, P. Sztajn, C. Edgington, and J. Confrey, "Teachers ' use of their mathematical knowledge for teaching in learning mathematics learning trajectory," pp. 149-175, 2014.

[7] A. S. Purnami, S. A. Widodo, and R. C. I. Prahmana, "The effect of team accelerated instruction on students ' mathematics achievement and learning motivation," in IOP Conf. Series: Journal of Physics: Conf. Series (ICE-STEM), 2018, pp. 1-5.

[8] J. W. Thomas, a Review of Research on Project-Based Learning. California, 2000, pp. 1-45.

[9] S. Bell, "Project-Based Learning for the 21st Century : Skills for," in The Clearing House, 2010, pp. 39-43. 
[10] M. M. Grant, "Getting a grip on project-based learning: Theory, cases, and recommendations," no. December 2002, 2014.

[11] M. Hohenwarter and K. Jones, "Ways of linking geometry and algebra: the case of Geogebra," Proc. Br. Soc. Res. into Learn. Math., vol. 27, no. 3, pp. 126-131, 2007.

[12] B. A. Saputo and S. Sumarni, "Desain Pembelajaran Garis Bagi Sudut dengan Pendekatan Matematika Realistik," Aksioma J. Pendidik. Mat. FKIP Univ. Muhammadiyah Metro, vol. 6, no. 1, pp. 136-150, 2017.

[13] B. A. Saputo, M. Prayito, and F. Nursyahidah, "Media Pembelajaran Geometri Menggunakan Pendekatan Pendidikan Matematika Realistik Berbasis GeoGebra," Kreano J. Mat. Kreat., vol. 6, no. 1, pp. 34-39, 2015

[14] B. A. Saputro, "Learning Media Development Approach with A Rectangle Problem Posing Based Geogebra," Infin. J. Math. Educ., vol. 6, no. 2, pp. 121-130, 2016.

[15] L. Cohen, L. Manion, P. Lecturer, K. Morrison, and S. Lecturer, Research Methods in Education. 2007.

[16] S. A. Widodo, R. C. I. Prahmana, A. S. Purnami, and Turmudi, "Teaching materials of algebraic equation," J. Phys. Conf. Ser., vol. 943, no. 1, 2017.

[17] S. Wurdinger et al., "learning in a mainstream middle school," 2008.

[18] and A. P. Phyllis C Blumenfeld, elliot Soloway, Ronald W Marx, Joseph S Krajcik, Mark Guzdial, "Motivating Project-Based Learning: Susraining the Doing, Supporting the Learning," Educ. Pyschologist1991, vol. 3, no. 26, pp. 369-398, 1991.

[19] M. Dogan and R. Icel, "The Role of Dynamic Geometry Software in the Process of Learning: GeoGebra Example about Triangles," Int. J. Hum. Sci., vol. 8, no. 1, pp. 1441-1458, 2011.

[20] N. of C. T. of Mathematics, Curricullum and Evaluation Standards for School Mathematics. Reston: NCTM, 2000.

[21] R. A. Saha, A. F. M. Ayub, and R. A. Tarmizi, "The effects of GeoGebra on mathematics achievement: Enlightening Coordinate Geometry learning," Procedia - Soc. Behav. Sci., vol. 8, no. December, pp. 686-693, 2010. 